MALLOMO: Journal of Community Service

https://jurnal.umsrappang.ac.id/mallomo/index

Vol 1, No 2, Juni 2021, pp 85-88

\title{
Kegiatan Pemberitaan dan Edukasi Sosialisasi Menjaga Keseimbangan Ekosistem Sungai Karang Mumus
}

\author{
Muhammad Arifin ${ }^{1}$, Hairunnisa ${ }^{2}$, Muhammad Naufal Al-Hadad S. ${ }^{3}$, Nindiani Kharimah ${ }^{4}$ \\ 1,2,3,4 Fakultas IImu Sosial dan Politik, Universitas Mulawarman \\ Email: andiarsalcobbo69@gmail.com
}

Abstract. The river is one of the ecosystems that support life in the community for daily activities such as bathing, washing, and as a livelihood. The Karang Mumus River is one of the tributaries of the Mahakam River which stretches for 17 KM from upstream to downstream, but the water quality in the Karang Mumus River is quite poor, due to household waste, company waste, and the buildup of sediment at the bottom of the river and houses built on the banks of the river. resulting in deteriorating water quality along the Karang Mumus River. To improve the quality of river water, the strategy used in this activity is through reporting on the condition of the Karang Mumus River and educating the public to maintain the Karang Mumus River ecosystem. It is hoped that after this the Samarinda City Community will maintain and care for the Karang Mumus River, so that the water quality in the river can improve for use in activities.

Abstrak. Sungai merupakan salah satu ekosistem pendukung kehidupan dalam masyarakat untuk beraktivitas sehari-hari seperti mandi, mencuci, dan sebagai matapencaharian. Sungai karang mumus merupakan salah satu anak sungai mahakam yang membentang sejauh 17 KM dari hulu menuju hilirnya, namun kualitas air pada sungai karang mumus terbilang cukup buruk, karena limbah rumah tangga, limbah perusahaan, serta penumpukan sendimen didasar sungai dan rumah yang dibangun di bantaran sungai mengakibatkan memburukya kualitas air disepanjang sungai karang mumus. Untuk memperbaiki kualitas air sungai, Strategi yang digunakan dalam kegiatan ini adalah melalui pemberitaan tentang 
keadaan Sungai Karang Mumus serta edukasi kepada masyarakat untuk menjaga ekosistem Sungai Karang Mumus. Diharapkan setelah ini Masyarakat Kota Samarinda menjaga serta merawat Sungai Karang Mumus, agar kualitas air pada sungai dapat membaik untuk digunakan dalam beraktivitas.

\author{
Keywords: \\ Karang Mumus \\ River, Water \\ Quality, River \\ Ecosystem \\ Pollution. \\ Kata Kunci: \\ Sungai Karang Mumus, \\ Kualitas Air, Pencemaran \\ Ekosistem Sungai.
}

Coresponden author:

Email: muhbibin@umsrappang.ac.id

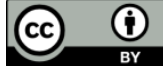

artikel dengan akses terbuka di bawah lisensi CC BY -4.0

\title{
PENDAHULUAN
}

Sungai Karang Mumus terletak di Samarinda, Kalimantan Timur. Aliran sungainya mencapai $17 \mathrm{Km}$ dan merupakan anak sungai Mahakam. Bagian hulu sungai terdapat Bendungan Benanga sedangkan bagian hilir sungai karang mumus bermuara langsung ke sungai Mahakam. Pada bagian tengah sungai ini aktivitas sosial dan pemukiman warga dapat dikatakan cukup padat sebab merupakan tempat berbagai jenis usaha seperti pasar, hotel, industri pengolahan tahu dan tempe, daerah pertanian, sekaligus peternakan.

Sebagian besar masyarakat yang tinggal di bantaran sungai masih menggunakan air sungai Karang Mumus untuk keperluan higiene sanitasi / Mandi Cuci Kakus (MCK). Menurut Peraturan Menteri Kesehatan Republik Indonesia Nomor 32 Tahun 2017 menyatakan bahwa air untuk keperluan higiene sanitasi digunakan untuk pemeliharaan kebersihan perorangan seperti mandi dan sikat gigi, sampai keperluan mencuci bahan pangan, peralatan dapur, pakaian, bahkan bahan baku air minum.

Untuk memenuhi segala keperluan tersebut, air yang digunakan harus bisa memenuhi syarat standar kesehatan. Namun seperti yang sudah kita ketahui bersama bahwasanya ekosistem yang ada di sungai Karang Mumus telah tercemar. Sehingga akan sangat berbahaya apabila masyarakat yang hidup di bantaran sungai Karang Mumus tetap memakai air sungai untuk kebutuhan hidup sehari-hari. Ekosistem sungai Karang Mumus ini sendiri telah mengalami pencemaran sejak beberapa tahun silam akibat berbagai faktor.

Ekosistem sungai merupakan jenis ekosistem air yang meliputi di sepanjang wilayah daerah aliran sungai, hulu sungai, hilir sungai, badan sungai, dan muara sungai, sehingga berbagai interaksi makhluk hidup dan lingkunannya yang meliputi kawasan sungai merupakan bagian dari ekosistem sungai. Ekosistem sungai memiliki suatu ciri khas sebagai berikut.

1. Air yang mengalir dari hulu menuju hilir.

2. Terdapat perubahan fisik dan kimia pada ekosistem sungai.

3. Tumbuhan dan Hewan pada ekosistem sungai dapat beradaptasi dengan lingkungannya.

Dalam Undang-undang Republik Indonesia Nomor 17 Tahun 2019 Tentang Sumber Daya Air Pasal 10J menyatakan bahwa (menjaga efektivitas, efisiensi, kualitas, dan ketertiban pelaksanaan Pengelolaan Sumber Daya Air pada Wilayah Sungai lintas negara, Wilayah Sungai lintas provinsi, dan 
Wilayah Sungai strategis nasional;), sehingga efesiensi serta kualitas sungai sangat harus diperhatikan terlebih lagi air tersebut digunakan dalam kehidupan sehari-hari masyarakat.

\section{Metode}

Strategi yang digunakan dalam kegiatan susur Sungai Karang Mumus adalah observasi dan pemberitaan. Observasi yang dilakukan mencakup pengamatan dan dokumentasi disepanjang Daerah Aliran Sungai (DAS). Pemberian edukasi kepada masyarakat melalui pemberitaan yang di publikasikan melalui media web FISIP UNMUL. Dalam kegiatan tersebut di hadiri oleh tenaga pendidik/dosen FISIP UNMUL dan Aggota Dinas PURP \& PERA Provinsi Kalimantan Timur, kegiatan susur Sungai Karang Mumus dilaksanakan dari hilir sungai menuju hulu pada hari rabu, 09 Juni 2021 Pukul 10.00-13.00 WITA.

\section{Hasil Dan Pembahasan}

Berdasarkan kegiatan susur Sungai Karang Mumus ini, terlihat banyak sampah seperti plastik, botol minuman, hingga limbah rumah tangga dan limbah pabrik yang tersebar di aliran sungai dari hulu menuju hilirnya, hal ini disebabkan oleh kegiatan masyarakat di bantaran sungai. Selain sampah dan limbah padatnya rumah penduduk yang bermukim di bantaran Sungai Karang Mumus membuat jarak antar sisi sungai menyempit, keadaan ini dapat mengganggu ekosistem air pada sungai.

Pemberian edukasi tentang keadaan Sungai Karang mumus di publikasikan pada hari kamis, 10 Juni 2021 melalui web FISIP UNMUL. Pemberitaan tersebut mencakup tentang keadaan Sungai Karang Mumus saat ini seperti limbah-limbah yang tersebar di seluruh aliran Sungai, hingga dampak rumah masyarakat yang bermukim di bantaran Sungai Karang Mumus. Pemberitaan ini guna mengedukasi seluruh Masyarakat Kota Samarinda untuk menjaga serta merawat aliran Sungai Karang Mumus untuk mengurangi sampah dan limbah yang terdapat pada aliran sungai serta meningkatkan kualitas air bersih pada ekosistem Sungai Karang Mumus.
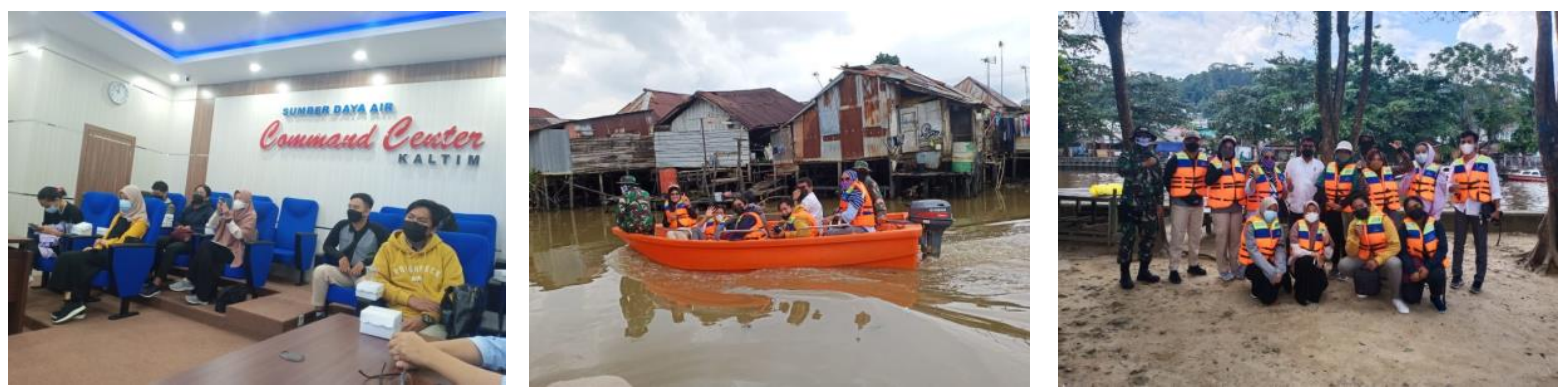

Gambar 1 Kegiatan susur Sungai Karang Mumus
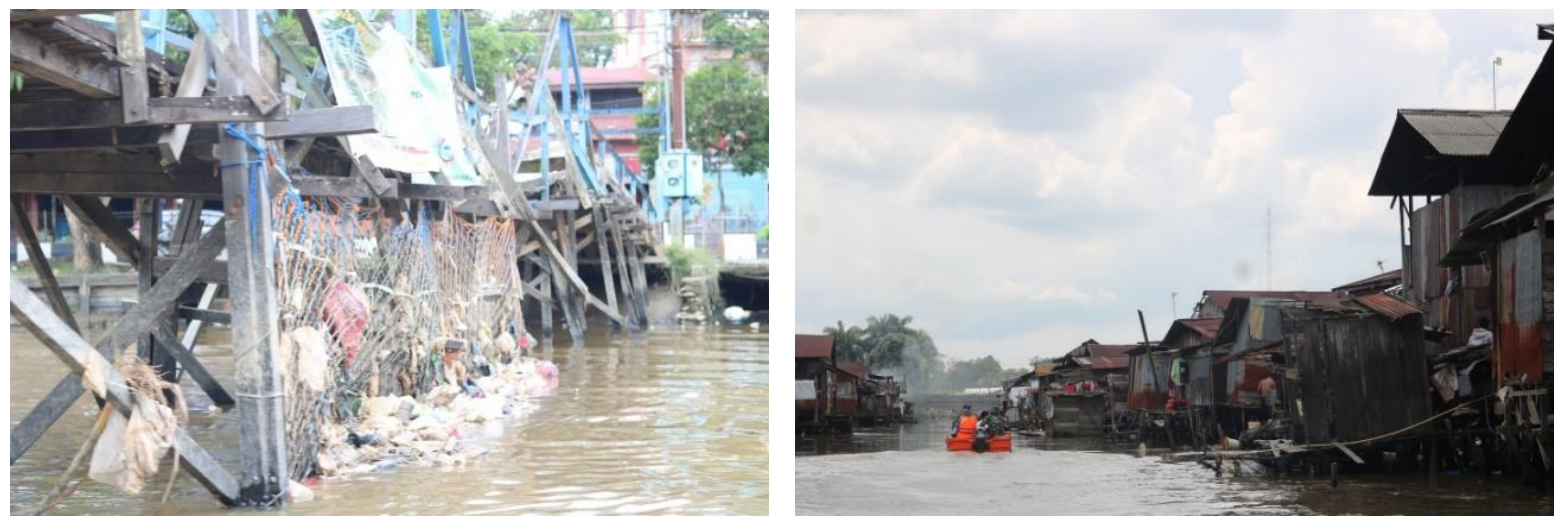

Gambar 2 Keadaan Sungai Karang Mumus 


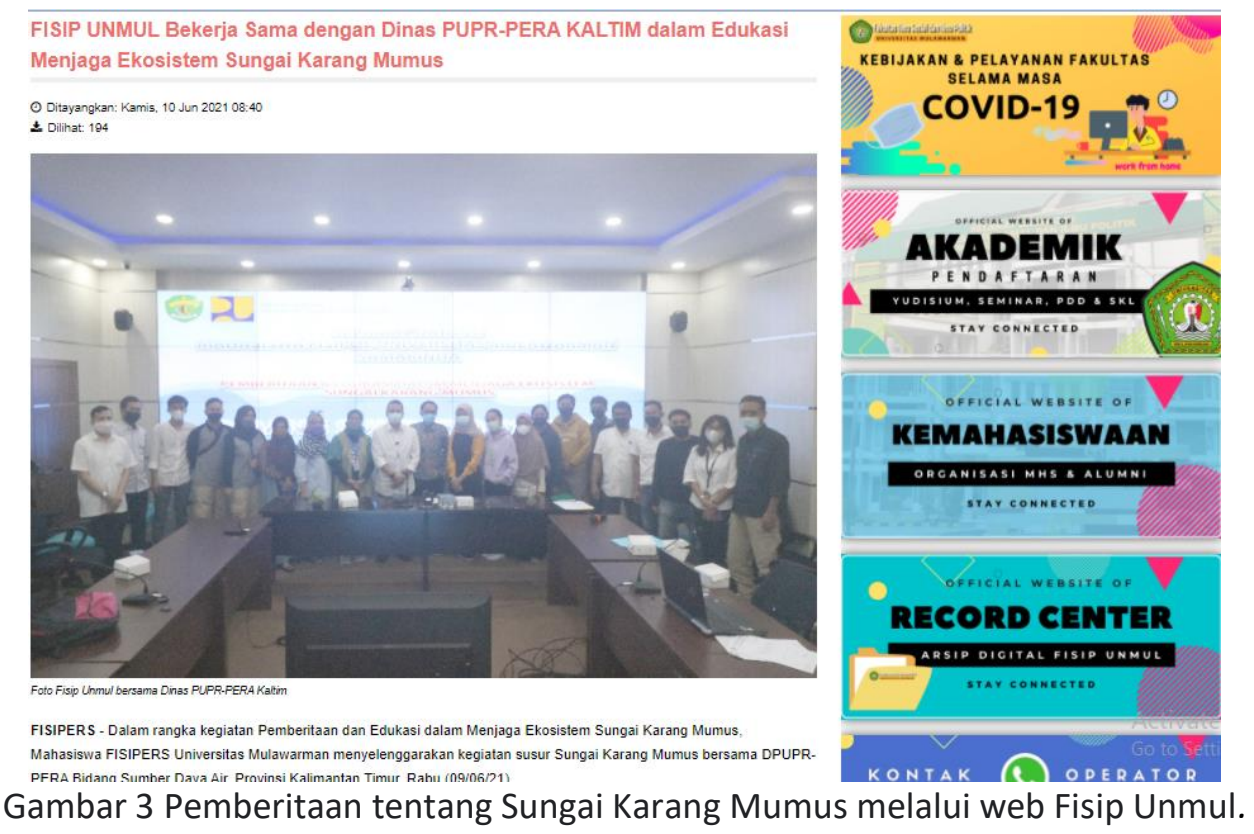

\section{Kesimpulan}

Pemberian edukasi tentang menjaga dan merawat aliran Sungai Karang Mumus kepada Masyarakat Kota Samarinda, merupakan salah satu pendukung agar menciptakan kualitas air yang bersih untuk digunakan dalam kehidupan sehari-hari Masyarakat Kota Samarinda, serta menjaga ekosistem yang terdapat pada aliran sungai tetap stabil untuk dihuni oleh sejumlah makhluk hidup.

Diharapkan setelah edukasi dipublis seluruh Masyarakat Kota Samarinda dapat:

1. Mengurangi sampah dan limbah yang dibuang langsung di Sungai.

2. Mengurangi kegiatan pembangunan rumah tinggal di bantaran Sungai.

Mengadakan/menambah kegiatan-kegiatan sosial yang bersifat memperbaiki aliran Sungai Karang Mumus.

\section{Daftar Rujukan}

Andi Daramusseng, Syamsir, (2020). Studi Kualitas Air Sungai Karang Mumus Ditinjau dari Parameter Escherichia coli Untuk Keperluan Higiene Sanitasi. Samarinda: Universitas Muhammadiyah Kalimantan Timur

Vita Pramaningsih, Slamet Suprayogi , Ig. L. Setyawan Purnamac, (2017). Kajian Persebaran Spasial Kualitas Air Sungai Karang Mumus, Samarinda, Kalimantan Timur. Yogyakarta: Universitas Gadjah Mada.

Desy Fatma, (2016). Ekosistem Sungai : Pengertian, Ciri-ciri, Komponen, Manfaatnya. https://ilmugeografi.com/ilmu-bumi/sungai/ekosistem-sungai Diakses Pada, (25 Juni 2021).

Ismail Saleh, (2020). Sungai Karang Mumus, Harus Diselamatkan Dari Pencemaran. https://muda.kompas.id/baca/2020/02/04/sungai-karang-mumus-harus-diselamatkan-daripencemaran/ Diakses Pada, (25 Juni 2021) 